Check for updates

Cite this: J. Mater. Chem. A, 2017, 5 , 21178

Received 9th June 2017

Accepted 11th September 2017

DOI: $10.1039 / c 7 t a 05031 c$

rsc.li/materials-a

\section{Revealing the relation between the structure, Li-ion conductivity and solid-state battery performance of the argyrodite $\mathrm{Li}_{6} \mathrm{PS}_{5} \mathrm{Br}$ solid electrolyte $\uparrow$}

\author{
Chuang Yu, ${ }^{a}$ Swapna Ganapathy, ${ }^{a}$ Ernst R. H. van Eck, ${ }^{b}$ Lambert van Eijck, ${ }^{a}$ \\ Shibabrata Basak, ${ }^{c}$ Yanyan Liu, ${ }^{d}$ Long Zhang, ${ }^{d}$ Henny W. Zandbergen ${ }^{c}$ \\ and Marnix Wagemaker (D)*a
}

Based on its high Li-ion conductivity, argyrodite $\mathrm{Li}_{6} \mathrm{PS}_{5} \mathrm{Br}$ is a promising solid electrolyte for all-solid-state batteries. However, more understanding is required on the relation between the solid electrolyte conductivity and the solid-state battery performance with the argyrodite structure, crystallinity and particle size that depend on the synthesis conditions. In the present study, this relationship is investigated using neutron and X-ray diffraction to determine the detailed structure and impedance as well as ${ }^{7} \mathrm{Li}$ solid state NMR spectroscopy to study the Li-ion kinetics. It is found that depending on the synthesis conditions the distribution of the $\mathrm{Br}$ dopant over the crystallographic sites in $\mathrm{Li}_{6} \mathrm{PS}_{5} \mathrm{Br}$ is inhomogeneous, and that this may be responsible for a larger mobile Li-ion fraction in the interfacial regions in the annealed argyrodite materials. Comparing the bulk and interfacial properties of the differently prepared $\mathrm{Li}_{6} \mathrm{PS}_{5} \mathrm{Br}$ materials, it is proposed that optimal solid-state battery performance requires a different particle size for the solid electrolyte only region and the solid electrolyte in the cathode mixture. In the electrolyte region, the grain boundary resistance is minimized by annealing the argyrodite $\mathrm{Li}_{6} \mathrm{PS}_{5} \mathrm{Br}$ resulting in relatively large crystallites. In the cathode mixture however, additional particle size reduction of the $\mathrm{Li}_{6} \mathrm{PS}_{5} \mathrm{Br}$ is required to provide abundant $\mathrm{Li}_{6} \mathrm{PS}_{5} \mathrm{Br}-\mathrm{Li}_{2} \mathrm{~S}$ interfaces that reduce the resistance of this rate limiting step in $\mathrm{Li}$-ion transport. Thereby the results give insight into how to improve solid-state battery performance by controlling the solid electrolyte structure.

\section{Introduction}

Inorganic solid electrolytes for all-solid-state Li-ion batteries are attracting significant attention because of the improved safety they provide in comparison with the conventional liquid electrolyte based Li-ion batteries., ${ }^{\mathbf{1} 2}$ Other potential advantages include improved chemical and electrochemical stability and more efficient cell packaging, allowing higher practical energy densities, using the same anode and cathode chemistries. One of the crucial parameters for solid electrolytes is their high room temperature Li-ion conductivity that for practical applications should be in the order of $10^{-4} \mathrm{~S} \mathrm{~cm}^{-1} .3,4$

\footnotetext{
${ }^{a}$ Department of Radiation Science and Technology, Delft University of Technology, Mekelweg 15, 2629JB Delft, The Netherlands. E-mail: M.Wagemaker@tudelft.nl

${ }^{b}$ Institute for Molecules and Materials, Radboud University Nijmegen, Heyendaalseweg 135, 6525 AJ Nijmegen, The Netherlands

'Kavli Institute of Nanoscience Delft, Department of Quantum Nanoscience, Delft University of Technology, Lorentzweg 1, 2628 CJ Delft, The Netherlands

${ }^{d}$ State Key Laboratory of Metastable, Materials Science and Technology, Yanshan University, Qinhuangdao, Hebei 066004, China
}

$\uparrow$ Electronic supplementary information (ESI) available. See DOI: $10.1039 / \mathrm{c} 7 \mathrm{ta0} 03031 \mathrm{c}$
Intensive research efforts have led to the discovery of several new solid electrolytes with high Li-ion conductivities including sulphides $\left(\mathrm{Li}_{2} \mathrm{~S}-\mathrm{P}_{2} \mathrm{~S}_{5}, \quad \mathrm{Li}_{2} \mathrm{~S}-\mathrm{SiS}_{2}\right.$, and $\left.\mathrm{Li}_{2} \mathrm{~S}-\mathrm{GeS}_{2}\right),{ }^{5-7}$ oxides $\left(\mathrm{Li}_{7} \mathrm{La}_{3} \mathrm{Zr}_{2} \mathrm{O}_{12} \text { and } \mathrm{Li}_{3 x} \mathrm{La}_{2 / 3-3 x} \mathrm{TiO}_{3}\right)^{8}$ and phosphates (LiPON, $\mathrm{Li}_{1+x} \mathrm{Al}_{x} \mathrm{Ge}_{2-x}\left(\mathrm{PO}_{4}\right)_{3}$, and $\left.\mathrm{Li}_{1+x} \mathrm{Ti}_{2-x} \mathrm{Al}_{x}\left(\mathrm{PO}_{4}\right)_{3}\right) .{ }^{\mathbf{1 , 2 , 9 , 1 0}}$ Among them, the chemically stable oxides and phosphates display relatively low ionic conductivities and high grain boundary resistances. ${ }^{\mathbf{1}}$ Sulphides generally offer higher conductivities ${ }^{\mathbf{1 1}}$ and their relatively low annealing temperatures, compared to the oxides and phosphates, apparently lead to a relatively low grain boundary resistance, ${ }^{2,12,13}$ which makes them promising solid electrolytes for solid-state cells. An important family of sulphide based solid electrolytes are the Li-argyrodites $\mathrm{Li}_{6} \mathrm{PS}_{5} \mathrm{X}$ $(\mathrm{X}=\mathrm{Cl}, \mathrm{Br}$ and $\mathrm{I}$ ) providing Li-ion conductivities in the range of $10^{-2}$ to $10^{-3} \mathrm{~S} \mathrm{~cm}^{-1}$ at room temperature. ${ }^{7}$ The high conductivity and the low costs of starting materials make the Li-argyrodites attractive for application in all-solid-state batteries. Previous work has demonstrated that the $\mathrm{Li}_{6} \mathrm{PS}_{5} \mathrm{Cl}$ argyrodite, with high Li-ion conductivity, can be synthesized by direct ball-milling followed by annealing, resulting in a good solid state $\mathrm{Li}-\mathrm{S}$ battery performance with both $\mathrm{S}$ and $\mathrm{Li}_{2} \mathrm{~S}$ cathodes. ${ }^{\text {14-17 }}$ Although for argyrodite solid electrolytes large electrochemical stability windows have been reported, ${ }^{\mathbf{1 8 , 1 9}}$ 
calculations indicate a much smaller window for sulphides ${ }^{20}$ with an upper limit just exceeding the potential of $\mathrm{Li}_{2} \mathrm{~S}$, motivating the use of $\mathrm{Li}_{2} \mathrm{~S}$ as a cathode material in combination with sulphide electrolytes.

To improve the all-solid-state battery performance, it is essential to develop an understanding of the influence of synthesis parameters and cycling conditions on the electrochemical performance of solid electrolytes. For argyrodite solid electrolytes, the annealing temperature appears to be very important for the Li-ion conductivity and electrochemical performance, as illustrated by the role of the halogen dopant position in the lattice, ${ }^{14}$ recently studied by DFT. ${ }^{21}$ The energy barriers for short range jumps and long range jumps were investigated by MD simulations and valence calculations indicating the detailed influence of the halogen on the diffusion mechanism. ${ }^{15,21}$ However, little is known about how annealing and ball milling strategies influence the bulk mobility as well as the macroscopic Li-ion conductivity, including across grain boundaries, and how this affects the solid-state battery performance. Additionally, little is known about the impact of the electrochemical (dis)charge window on the cycle life, which is in particular relevant in the context of the predicted limited electrochemical stability window for these sulfide electrolytes.

In the present work, a detailed study of the effect of annealing on the Li-ion dynamics in the argyrodite $\mathrm{Li}_{6} \mathrm{PS}_{5} \mathrm{Br}$ solid electrolyte has been performed. By employing both impedance spectroscopy and spin-lattice relaxation (SLR) NMR measurements, differences in the local Li-ion mobility and bulk diffusion as well as the impact of grain boundaries are revealed between differently prepared $\mathrm{Li}_{6} \mathrm{PS}_{5} \mathrm{Br}$ solid electrolyte materials. Combined Rietveld refinement of neutron and X-ray powder diffraction data were performed to probe structural differences between the prepared $\mathrm{Li}_{6} \mathrm{PS}_{5} \mathrm{Br}$ materials. Transmission electron microscopy (TEM) measurements were performed to investigate the crystallinity and the distribution of the Br dopant. Finally, cyclic voltammetry (CV) was performed to determine the optimum (dis)charge voltage window for the nano- $\mathrm{Li}_{2} \mathrm{~S} / \mathrm{Li}_{6} \mathrm{PS}_{5} \mathrm{Br} / \mathrm{In}$ solid-state cells. By employing the optimized electrochemical window for (dis)charging, a significant difference in the performance is observed for the differently prepared solid electrolytes, where only the solid-state cell using annealed nano-sized $\mathrm{Li}_{6} \mathrm{PS}_{5} \mathrm{Br}$ as the solid electrolyte maintained capacities above $500 \mathrm{~mA} \mathrm{~h} \mathrm{~g}{ }^{-1}$ (per gram of active material) for 25 cycles.

\section{Experimental}

Reagent-grade $\mathrm{Li}_{2} \mathrm{~S}$ (99.98\%, Sigma-Aldrich), $\mathrm{P}_{2} \mathrm{~S}_{5}$ (99\%, SigmaAldrich), and $\operatorname{LiBr}(99.0 \%$, Sigma-Aldrich) crystalline powders were used as starting materials. The required amount of the starting materials was ball milled together in a tungsten carbide (WC) coated (inner) stainless steel jar with $10 \mathrm{WC}$ balls (8 $\mathrm{g}$ per ball) in an argon filled glovebox $\left(\mathrm{H}_{2} \mathrm{O}, \mathrm{O}_{2}<0.3 \mathrm{ppm}\right)$ because of the reactivity of the sample with oxygen and moisture. The total weight of the mixture was almost 2.0 grams, and the ball milling speed was fixed at $500 \mathrm{rpm}$. The milling duration was varied to find the optimal milling time. After subsequent milling times, a small amount of powder was collected to perform powder XRD measurements. After the ball milling process, half of the sample was set aside as the ball-milled only $\mathrm{Li}_{6} \mathrm{PS}_{5} \mathrm{Br}\left(\mathrm{Li}_{6} \mathrm{PS}_{5} \mathrm{Br}\right)$, and the remaining material was sealed in a quartz tube and annealed at $300{ }^{\circ} \mathrm{C}$ for 5 hours to obtain the annealed $\mathrm{Li}_{6} \mathrm{PS}_{5} \mathrm{Br}\left(\mathrm{AN}^{-\mathrm{Li}_{6}} \mathrm{PS}_{5} \mathrm{Br}\right)$ solid electrolyte. The $\mathrm{AN}^{-\mathrm{Li}_{6}} \mathrm{PS}_{5} \mathrm{Br}$ was further milled with a rotation speed of $450 \mathrm{rpm}$ for $4 \mathrm{~h}$ to obtain the AN-BM-Li ${ }_{6} \mathrm{PS}_{5} \mathrm{Br}$ sample.

Powder XRD patterns were collected over a $2 \theta$ range of $10-80^{\circ}$ to identify the crystalline phases of the different samples using $\mathrm{Cu}_{\mathrm{K} \alpha} \mathrm{X}$-rays $(1.5406 \AA$ at $45 \mathrm{kV}$ and $40 \mathrm{~mA}$ ) on an X'Pert Pro $\mathrm{X}$-ray diffractometer (PANalytical). To prevent the reaction with moisture and oxygen, the powders were sealed in an airtight XRD sample holder in an argon filled glove box. Neutron diffraction data were collected on a new neutron powder diffractometer PEARL of the TU Delft. ${ }^{22}$ Data were collected at room temperature using the (533) reflection of the germanium monochromator $(\lambda=1.665 \AA)$. The sample was loaded under argon in a $6 \mathrm{~mm}$ diameter air-tight vanadium sample can. The sample was measured for 18 hours from 10.4-160 degrees $2 \theta$. The sample can is under vacuum during the data collection. The data treatment consisted of a relative correction for the detection efficiency of (each of) the 1408 detector pixels and a subtraction of the background, caused by the instrument and the sample can. The X-ray and neutron diffraction data were refined simultaneously using the Rietveld method implemented in GSAS. ${ }^{23}$ Besides the atomic and lattice parameters, the absorption and line-broadening parameters, the crystal phase fractions, and the background were fitted. The $\mathrm{S}$ and $\mathrm{Br}$ occupancies on both the 4a and 4c crystallographic sites were restricted by setting the sum to 1 on each site.

For the TEM investigation, a suspension of each $\mathrm{Li}_{6} \mathrm{PS}_{5} \mathrm{Br}$ sample in hexane was prepared which was dropcast onto a standard gold grid with a holey carbon film, inside an argonfilled glove box. To prevent any contact with air TEM grids with the sample were loaded into a custom-made vacuum transfer TEM holder. TEM measurements were carried out on a FEITecnai operating at $200 \mathrm{kV}$. The morphology of the materials and the corresponding distribution of $\mathrm{S}, \mathrm{P}$, and $\mathrm{Br}$ were investigated by SEM and EDS.

The ionic conductivities of the $\mathrm{Li}_{6} \mathrm{PS}_{5} \mathrm{Br}$ electrolyte materials were determined by AC impedance. Stainless-steel disks were attached on both faces of the $10 \mathrm{~mm}$ diameter powder pellets. ${ }^{16,17} \mathrm{AC}$ impedance measurements were performed using an Autolab (PGSTAT302N) in the frequency range of $0.1 \mathrm{~Hz}$ to $1 \mathrm{MHz}$ with an applied voltage of $0.05 \mathrm{~V}$.

Solid-state NMR measurements were performed on a Chemagnetics 400 Infinity spectrometer $\left(B_{0}=9.4 T\right)$, operating at the $155.506 \mathrm{MHz}^{7} \mathrm{Li}$ resonance frequency. The $\pi / 2$ pulse length was determined to be $3.1 \mu \mathrm{s}$ with an RF field strength of $85 \mathrm{kHz}$. Chemical shifts were referenced with respect to a $0.1 \mathrm{M} \mathrm{LiCl}$ solution. The air sensitive $\mathrm{Li}_{6} \mathrm{PS}_{5} \mathrm{Br}$ materials were sealed in custom-made Teflon tubes in an argon filled glove box $\left(\mathrm{H}_{2} \mathrm{O}, \mathrm{O}_{2}\right.$ $<0.3 \mathrm{ppm}$ ). Variable temperature measurements were performed using a $5 \mathrm{~mm}$ static goniometer probe. For all three $\mathrm{Li}_{6} \mathrm{PS}_{5} \mathrm{Br}$ samples spectra were acquired in the temperature range of $-100{ }^{\circ} \mathrm{C}$ to $+180{ }^{\circ} \mathrm{C}$. $T_{1}$ relaxation times were 
determined at various temperatures using a saturation recovery experiment. Corresponding $T_{1 \rho}$ measurements were performed using the spin-lock method at a lock frequency of $20 \mathrm{kHz}$. Additional single pulse experiments were performed at different temperatures to determine the evolution of the line-width as a function of temperature employing a spectral width of $250 \mathrm{kHz}$. In each case a recycle delay of $3 T_{1}$ was used.

Laboratory-scale solid-state $\mathrm{Li}_{2} \mathrm{~S} / \mathrm{Li}_{6} \mathrm{PS}_{5} \mathrm{Br} / \mathrm{In}$ batteries were prepared. Commercial $\mathrm{Li}_{2} \mathrm{~S}$ was first milled with a rotation speed of $500 \mathrm{rpm}$ for $4 \mathrm{~h}$, and then milled with $\mathrm{Li}_{6} \mathrm{PS}_{5} \mathrm{Br}, \mathrm{AN}$ $\mathrm{Li}_{6} \mathrm{PS}_{5} \mathrm{Br}$ and $\mathrm{AN}-\mathrm{BM}-\mathrm{Li}_{6} \mathrm{PS}_{5} \mathrm{Br}$ separately and super $\mathrm{P}$ (TIMCAL) with a weight ratio of $4: 4: 2$ using a rotation speed of $450 \mathrm{rpm}$ for $2 \mathrm{~h}$ to obtain the final cathode mixture. A two-layer pellet, $10 \mathrm{~mm}$ in diameter, consisting of $12 \mathrm{mg}$ of the described cathode mixture and $88 \mathrm{mg} \mathrm{Li}_{6} \mathrm{PS}_{5} \mathrm{Br}, \mathrm{AN}-\mathrm{Li}_{6} \mathrm{PS}_{5} \mathrm{Br}$, or AN-BM$\mathrm{Li}_{6} \mathrm{PS}_{5} \mathrm{Br}$ solid electrolyte, was obtained by pressing the electrode and electrolyte powders by applying 6 tons of pressure. A piece of In foil was subsequently attached to the other side. Finally, the full solid-state battery pellet was pressed with 2 tons of pressure for $30 \mathrm{~s}$. Cyclic voltammetry (CV) measurements of the solid-state battery with the $\mathrm{AN}-\mathrm{Li}_{6} \mathrm{PS}_{5} \mathrm{Br}$ solid electrolyte were performed at different voltage windows applying a sweep rate of $0.5 \mathrm{mV} \mathrm{s}^{-1}$ to determine the optimum (dis)charge voltage window. The assembled cells, either with $\mathrm{Li}_{6} \mathrm{PS}_{5} \mathrm{Br}, \mathrm{AN}-\mathrm{Li}_{6} \mathrm{PS}_{5} \mathrm{Br}$ or $\mathrm{AN}-\mathrm{BM}-\mathrm{Li}_{6} \mathrm{PS}_{5} \mathrm{Br}$, were charged and discharged applying a current density of $0.064 \mathrm{~mA} \mathrm{~cm} \mathrm{~cm}^{-2}$ between 0 and $3.5 \mathrm{~V} v s$. In order to evaluate the electrochemical performance. The obtained capacity was normalized by the weight of $\mathrm{Li}_{2} \mathrm{~S}$ in the cathode.

\section{Results and discussion}

\section{Impedance, diffraction and TEM characterization of $\operatorname{Li}_{6} \mathbf{P S}_{5} \mathrm{Br}$}

The XRD patterns of the $\mathrm{Li}_{6} \mathrm{PS}_{5} \mathrm{Br}$ samples synthesized by mechanical milling at $500 \mathrm{rpm}$ for different durations are shown in Fig. 1a. As illustrated, the diffraction peaks of the sample milled at $110 \mathrm{rpm}$ for 1 hour could be indexed to the starting materials $\mathrm{Li}_{2} \mathrm{~S}, \mathrm{LiBr}$ and $\mathrm{P}_{2} \mathrm{~S}_{5}$. This step appears to be necessary in order to mix the raw materials homogeneously. After that, the milling speed was increased to $500 \mathrm{rpm}$ to provide the mechanical energy necessary to obtain the $\mathrm{Li}_{6} \mathrm{PS}_{5} \mathrm{Br}$ phase. After $1 \mathrm{~h}$ of milling, the initially sharp diffraction peaks

(a)

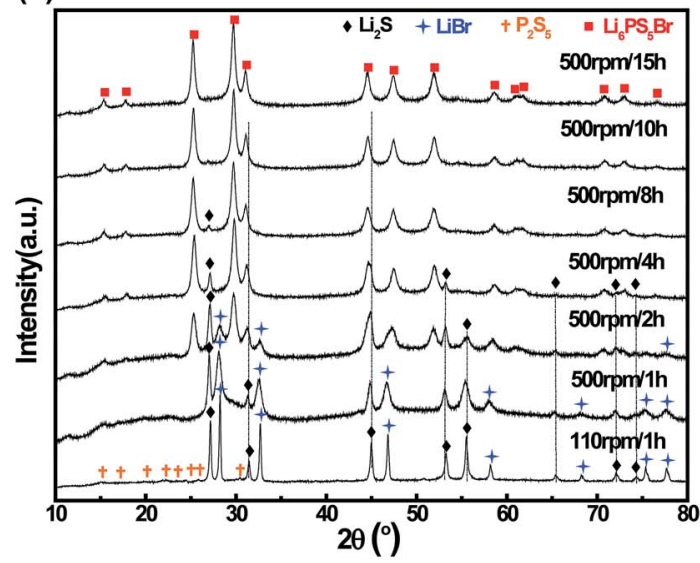

(b)

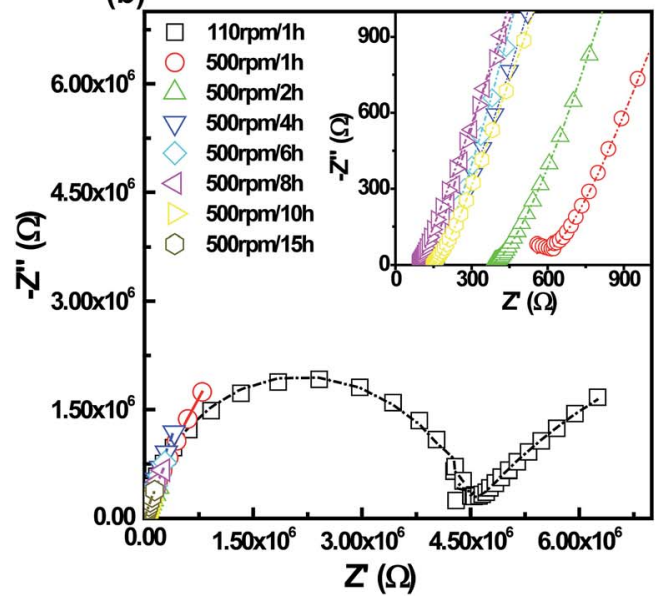

(c)

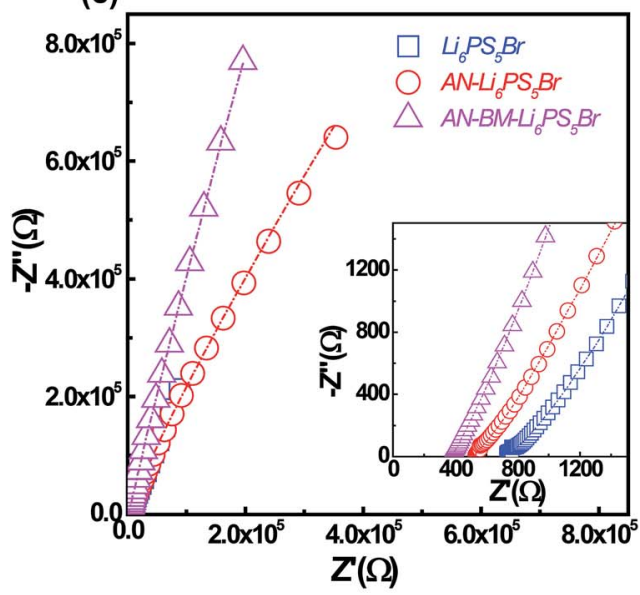

Fig. 1 (a) XRD patterns of the $\mathrm{Li}_{2} \mathrm{~S}, \mathrm{P}_{2} \mathrm{~S}_{5}$ and $\mathrm{LiBr}$ mixtures ball-milled for different milling durations. (b) Complex impedance plots for the samples ball-milled for different durations. The dotted lines represent fits using an equivalent circuit $\left(R_{\text {bulk }} Q_{\text {bulk }}\right)\left(R_{\mathrm{gb}} Q_{\mathrm{gb}}\right) Q$. (c) The $A C$ impedance results of $\mathrm{Li}_{6} \mathrm{PS}_{5} \mathrm{Br}$ (ball milled for 8 hours at $500 \mathrm{rpm}$ ) (blue), $\mathrm{AN}-\mathrm{Li}_{6} \mathrm{PS}_{5} \mathrm{Br}\left(\mathrm{Li}_{6} \mathrm{PS}{ }_{5} \mathrm{Br}\right.$ subsequently annealed at $300{ }^{\circ} \mathrm{C}$ for 5 hours) (red) and $\mathrm{AN}-\mathrm{BM}-$ $\mathrm{Li}_{6} \mathrm{PS}_{5} \mathrm{Br}$ (AN- $\mathrm{Li}_{6} \mathrm{PS}_{5} \mathrm{Br}$ subsequently ball milled for 4 hours at $450 \mathrm{rpm}$ ) (pink). The dotted lines represent fits using an equivalent circuit $\left(R_{\mathrm{bulk}} Q_{\mathrm{bulk}}\right)\left(R_{\mathrm{gb}} Q_{\mathrm{gb}}\right) Q$. 
originating from the $\mathrm{Li}_{2} \mathrm{~S}$ phase broadened, indicating a decrease in particle size. Moreover, a halo pattern located in the low $2 \theta$ region appeared, indicating the formation of an amorphous phase. ${ }^{24}$ As the milling duration increases, diffraction peaks at 25.2, 29.7, 31.1 and $51.9^{\circ}$ appear which can be attributed to the $\mathrm{Li}_{6} \mathrm{PS}_{5} \mathrm{Br}$ phase. Compared to the pattern measured after $1 \mathrm{~h}$ of milling, the intensity of the $\mathrm{Li}_{2} \mathrm{~S}$ diffraction peaks decreases and after a milling time of $10 \mathrm{~h}$, the diffraction peak due to $\mathrm{Li}_{2} \mathrm{~S}$ located at $53.3^{\circ}$ disappears completely.

The influence of the milling time on the Li-ion conductivity is investigated by impedance spectroscopy. The resistance of the mixture decreases sharply with increasing milling duration until a constant value is obtained after $8 \mathrm{~h}$ of milling, as shown in Fig. 1b. The increase in $\mathrm{Li}^{+}$conductivity during the milling process is associated with the concurrent decrease of the poorly conducting $\mathrm{Li}_{2} \mathrm{~S}$ phase and the increase of the Li-ion conducting $\mathrm{Li}_{6} \mathrm{PS}_{5} \mathrm{Br}$ phase in the mixture. Because the material obtained after 8 hours reaches the maximum conductivity, this material is used for further investigations and referred to as $\mathrm{Li}_{6} \mathrm{PS}_{5} \mathrm{Br}$. Subsequently, this material is annealed at $300{ }^{\circ} \mathrm{C}$ for $5 \mathrm{~h}$ and the resulting material is referred to as $\mathrm{AN}-\mathrm{Li}_{6} \mathrm{PS}_{5} \mathrm{Br}$. Finally, the $\mathrm{AN}$ $\mathrm{Li}_{6} \mathrm{PS}_{5} \mathrm{Br}$ is ball-milled at a rotation speed of $450 \mathrm{rpm}$ for 4 hours, the resulting material of which is referred to as AN-BM$\mathrm{Li}_{6} \mathrm{PS}_{5} \mathrm{Br}$. The AC impedance and fitting results of the $\mathrm{Li}_{6} \mathrm{PS}_{5} \mathrm{Br}$, $\mathrm{AN}-\mathrm{Li}_{6} \mathrm{PS}_{5} \mathrm{Br}$ and $\mathrm{AN}-\mathrm{BM}-\mathrm{Li}_{6} \mathrm{PS}_{5} \mathrm{Br}$ samples are shown in Fig. 1c. These result in bulk and grain boundary resistances of (924.8 \pm 16.58) and $(3.02 \pm 0.64) \times 10^{6} \Omega$ for $\mathrm{Li}_{6} \mathrm{PS}_{5} \mathrm{Br},(516.8 \pm 32.28)$ and $(619.9 \pm 22.26) \Omega$ for $\mathrm{AN}-\mathrm{Li}_{6} \mathrm{PS}_{5} \mathrm{Br}$ and $(381.7 \pm 10.81)$ and $(686.8 \pm 35.88) \Omega$ for $\mathrm{AN}-\mathrm{BM}-\mathrm{Li}_{6} \mathrm{PS}_{5} \mathrm{Br}$. The corresponding room temperature bulk conductivities are $6.20 \times 10^{-4} \mathrm{~S} \mathrm{~cm}^{-1}, 1.11 \times$ $10^{-3} \mathrm{~S} \mathrm{~cm}^{-1}$ and $1.38 \times 10^{-3} \mathrm{~S} \mathrm{~cm}^{-1}$ for $\mathrm{Li}_{6} \mathrm{PS}_{5} \mathrm{Br}$ AN-Li ${ }_{6} \mathrm{PS}_{5} \mathrm{Br}$ and $\mathrm{AN}-\mathrm{BM}-\mathrm{Li}_{6} \mathrm{PS}_{5} \mathrm{Br}$ respectively. The annealing process increases the conductivity significantly and the subsequent ball milling step appears to further increase the bulk conductivity. Annealing dramatically lowers the grain boundary resistance as observed by impedance spectroscopy, whereas the subsequent ball milling process results in a small increase of the grain boundary resistance. Perhaps the most surprising result is that the bulk conductivity of $\mathrm{AN}-\mathrm{BM}-\mathrm{Li}_{6} \mathrm{PS}_{5} \mathrm{Br}$ is larger than that of the $\mathrm{AN}-\mathrm{Li}_{6} \mathrm{PS}_{5} \mathrm{Br}$, suggesting that decreasing the particle size of $\mathrm{AN}-\mathrm{Li}_{6} \mathrm{PS}_{5} \mathrm{Br}$ enhances the Li-ion bulk conductivity. However, it should be realized that for these geometrically complex systems it is difficult to distinguish the bulk conductivity from the grain boundary resistance using impedance spectroscopy.

Both powder neutron and X-ray diffraction were performed, the data of which were simultaneously refined in the cubic $F \overline{4} 3 m$ space group using the Rietveld method as implemented in GSAS. $^{23}$ The neutron powder patterns and the X-ray patterns of the three $\mathrm{Li}_{6} \mathrm{PS}_{5} \mathrm{Br}$ materials are shown in Fig. 2 and the crystallographic parameters resulting from the refinements are provided in Table S1 of the ESI. $\dagger$ The smaller line width of the reflections of the $\mathrm{AN}-\mathrm{Li}_{6} \mathrm{PS}_{5} \mathrm{Br}$ material in Fig. 2(c and $\mathrm{d}$ ) compared to that of $\mathrm{Li}_{6} \mathrm{PS}_{5} \mathrm{Br}$ in Fig. $2(\mathrm{a}$ and $\mathrm{b}$ ) indicates an increase in crystallinity and crystallite size upon annealing. From the refinement of the patterns, assuming only size broadening, the average crystallite size of the $\mathrm{Li}_{6} \mathrm{PS}_{5} \mathrm{Br}$ material is $15 \mathrm{~nm}$ and of the $\mathrm{AN}-\mathrm{Li}_{6} \mathrm{PS}_{5} \mathrm{Br}$ material is $74 \mathrm{~nm}$. As shown in Fig. 2(e and $\mathrm{f}$ ), subsequent ball milling of $\mathrm{AN}-\mathrm{Li}_{6} \mathrm{PS}_{5} \mathrm{Br}$ resulting in the $\mathrm{AN}-\mathrm{BM}-\mathrm{Li}_{6} \mathrm{PS}_{5} \mathrm{Br}$ material increases the width of the reflections again, leading to an average crystallite size of $22 \mathrm{~nm}$ from the refinement. The substantial background observed in the diffraction pattern of $\mathrm{Li}_{6} \mathrm{PS}_{5} \mathrm{Br}$, especially visible at low angles in Fig. 2a, indicates the presence of a significant amorphous fraction. The much lower background in Fig. 2c indicates that, as expected based on the glass temperature of $265{ }^{\circ} \mathrm{C}$, annealing the sample at $300^{\circ} \mathrm{C}$ converts most of the amorphous fraction to the crystalline $\mathrm{Li}_{6} \mathrm{PS}_{5} \mathrm{Br}$ phase. For the AN-BM-Li ${ }_{6}$ $\mathrm{PS}_{5} \mathrm{Br}$ material, the background increases again, suggesting that the final ball milling procedure increases the amorphous fraction again. However, the larger lattice parameters of the AN-BM$\mathrm{Li}_{6} \mathrm{PS}_{5} \mathrm{Br}$ material compared to that of the $\mathrm{Li}_{6} \mathrm{PS}_{5} \mathrm{Br}$ material and the smaller background suggest that the crystalline fraction of the AN-BM- $\mathrm{Li}_{6} \mathrm{PS}_{5} \mathrm{Br}$ material is larger than that of the $\mathrm{Li}_{6} \mathrm{PS}_{5} \mathrm{Br}$ material, which is also confirmed by the TEM experiments discussed in the next paragraph.

The simultaneous refinement of the X-ray and neutron diffraction data allows us to determine the average amount of $\mathrm{Br}$ and $S$ on the $4 \mathrm{a}(0,0,0)$ and $4 \mathrm{c}(0.25,0.25,0.25)$ crystallographic sites. Similar to what was found for $\mathrm{Li}_{6} \mathrm{PS}_{5} \mathrm{Cl}$ argyrodite, ${ }^{\mathbf{1 4}}$ there is a slight preference for $\mathrm{Br}$ to occupy the $4 \mathrm{c}$ site as shown in Table S1 of the ESI. $\dagger$ Interestingly, upon annealing, the $\mathrm{Br}$ occupancy on the 4c site increases significantly, while decreasing on the $4 \mathrm{a}$ site, keeping the total $\mathrm{Br}$ content close to the intended $\mathrm{Li}_{6} \mathrm{PS}_{5} \mathrm{Br}$ composition. Note that during the fitting the total occupancy of the $4 \mathrm{a}$ site and of the $4 \mathrm{c}$ site by $\mathrm{Br}$ and $\mathrm{S}$ is restricted to unity. The increase of the average $\mathrm{Br}_{4 \mathrm{c}}$ occupancy in the $\mathrm{AN}-\mathrm{Li}_{6} \mathrm{PS}_{5} \mathrm{Br}$ sample indicates that the $\mathrm{Br}_{4 \mathrm{c}}$ occupancy in the amorphous phase of the $\mathrm{Li}_{6} \mathrm{PS}_{5} \mathrm{Br}$ sample, which turns crystalline upon annealing, is larger compared to the crystalline fraction of the $\mathrm{Li}_{6} \mathrm{PS}_{5} \mathrm{Br}$ sample. Vice versa the $\mathrm{Br}_{4 \mathrm{a}}$ occupancy decreases upon annealing, keeping the total Br occupancy, and hence the $\mathrm{Br}$ concentration approximately constant and close to the intended composition as shown in Table S1. $\dagger$

Subsequent ball milling, going from the $\mathrm{AN}-\mathrm{Li}_{6} \mathrm{PS}_{5} \mathrm{Br}$ to the AN-BM- $\mathrm{Li}_{6} \mathrm{PS}_{5} \mathrm{Br}$ sample, decreases the $\mathrm{Br}_{4 \mathrm{c}}$ occupancy (and increases the $\mathrm{Br}_{4 \mathrm{a}}$ occupancy) again to a value still larger (smaller for $\mathrm{Br}_{4 \mathrm{a}}$ ) compared to that of the $\mathrm{Li}_{6} \mathrm{PS}_{5} \mathrm{Br}$ sample. Assuming that upon annealing the amorphous material crystallizes around the crystalline core of the $\mathrm{Li}_{6} \mathrm{PS}_{5} \mathrm{Br}$ sample, it is found that the $4 \mathrm{c}(4 \mathrm{a})$ occupancy in the center of the particles is larger (smaller for $\mathrm{Br}_{4 \mathrm{a}}$ ) compared to that at the surface of the particles. Hence these results indicate that, although the $\mathrm{Br}$ appears to be homogeneously distributed through the particles, the relative $4 \mathrm{a} / 4 \mathrm{c}$ site occupancy is inhomogeneous throughout the particles.

Recent molecular dynamics simulations have that the distribution of the halogen dopant over the $4 \mathrm{a}$ and $4 \mathrm{c}$ sites strongly influences the Li-ion conductivity. ${ }^{21}$ Therefore, the suggested inhomogeneous site distribution of the $\mathrm{Br}$ dopant in the present argyrodite materials is likely to result in an inhomogeneous Li-ion conductivity, control over which may be an important parameter for the design of optimal solid electrolytes. 
(a)

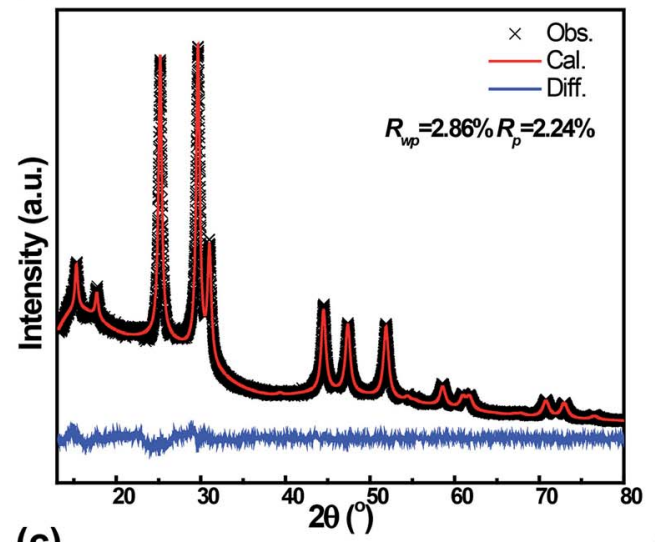

(c)

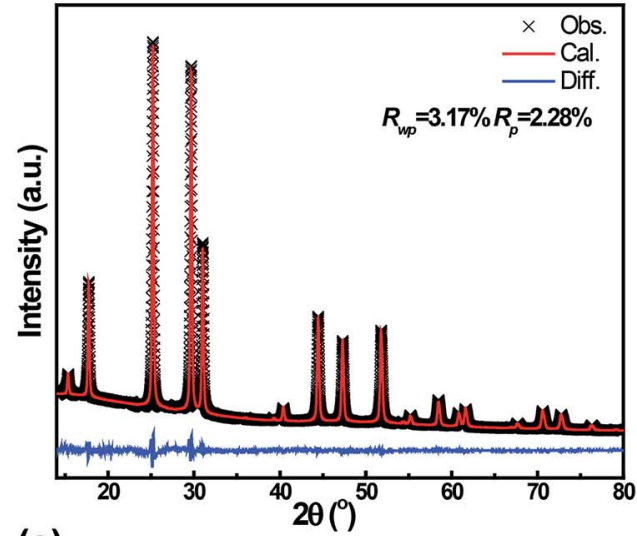

(e)

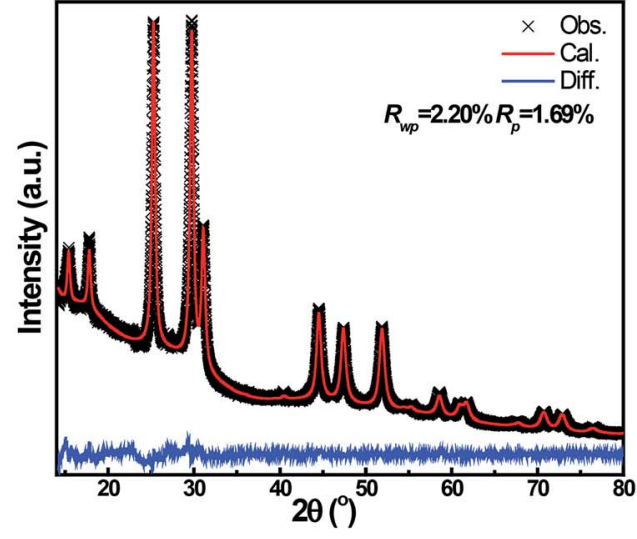

(b)

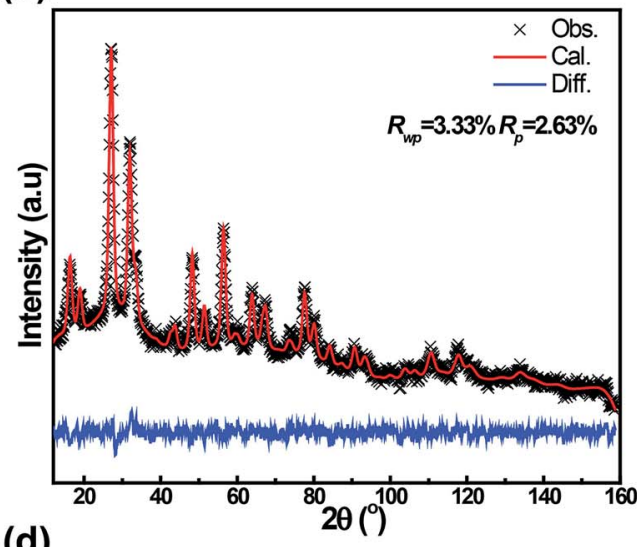

(d)

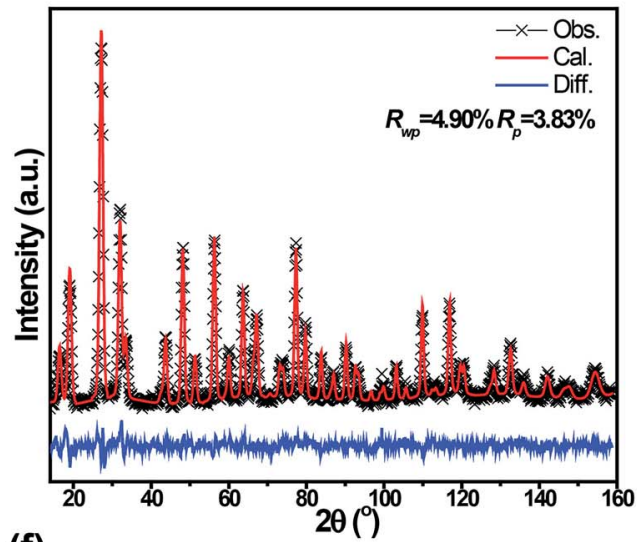

(f)

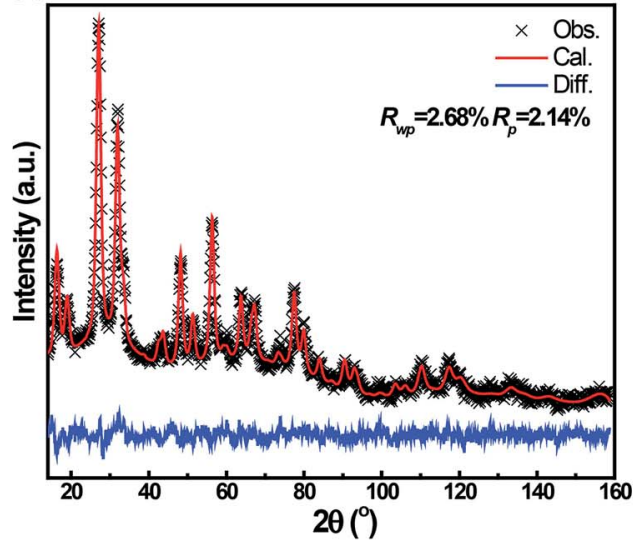

Fig. 2 Room temperature $X$-ray and neutron diffraction patterns including Rietveld refinement of the (a and b) $\mathrm{Li}_{6} \mathrm{PS}_{5} \mathrm{Br}$, (c and d) $\mathrm{AN}$ - $\mathrm{Li}_{6} \mathrm{PS}{ }_{5} \mathrm{Br}$, and (e and f) AN-BM- $\mathrm{Li}_{6} \mathrm{PS}_{5} \mathrm{Br}$, respectively.

Fig. 3a and c show the bright-field TEM (BF-TEM) images of the $\mathrm{Li}_{6} \mathrm{PS}_{5} \mathrm{Br}$ and $\mathrm{AN}-\mathrm{BM}-\mathrm{Li}_{6} \mathrm{PS}_{5} \mathrm{Br}$ samples respectively and Fig. $3 \mathrm{~b}$ and $\mathrm{d}$ show the electron diffraction patterns of $\mathrm{Li}_{6} \mathrm{PS}_{5} \mathrm{Br}$ and $\mathrm{AN}-\mathrm{BM}-\mathrm{Li}_{6} \mathrm{PS}_{5} \mathrm{Br}$ samples, acquired from the particles shown in $3 \mathrm{a}$ and $3 \mathrm{c}$ respectively. The presence of a ring-like diffraction pattern for the $\mathrm{Li}_{6} \mathrm{PS}_{5} \mathrm{Br}$ sample, without distinct diffraction spots, indicates the presence of a significant fraction of the amorphous material. After subsequent annealing and ball milling, the diffraction spots for AN-BM- $\mathrm{Li}_{6} \mathrm{PS}_{5} \mathrm{Br}$ become more distinct, indicating that the material becomes more crystalline, as shown in Fig. 3d. The Scanning Tunnel
Microscope-Energy Dispersive X-ray (STEM-EDX) mapping of the $\mathrm{Li}_{6} \mathrm{PS}_{5} \mathrm{Br}$ sample (Fig. 3f) shows a homogeneous distribution of $\mathrm{S}, \mathrm{P}$ and $\mathrm{Br}$, indicating that this mechanical milling route is an effective synthesis method to prepare $\mathrm{Li}_{6} \mathrm{PS}_{5} \mathrm{Br}$. Since the AN$\mathrm{Li}_{6} \mathrm{PS}_{5} \mathrm{Br}$ and $\mathrm{AN}-\mathrm{BM}-\mathrm{Li}_{6} \mathrm{PS}_{5} \mathrm{Br}$ are prepared starting from the $\mathrm{Li}_{6} \mathrm{PS}_{5} \mathrm{Br}$ sample with subsequent annealing and ball-milling processes, the $\mathrm{S}, \mathrm{P}$ and $\mathrm{Br}$ in those samples are also expected to remain homogeneously distributed. SEM images displayed in Fig. S2 of the ESI, $\dagger$ shows an interconnected platelet like structure for the $\mathrm{Li}_{6} \mathrm{PS}_{5} \mathrm{Br}$ and $\mathrm{AN}-\mathrm{Li}_{6} \mathrm{PS}_{5} \mathrm{Br}$ materials, whereas the final ball milling step destroys this morphology resulting in 


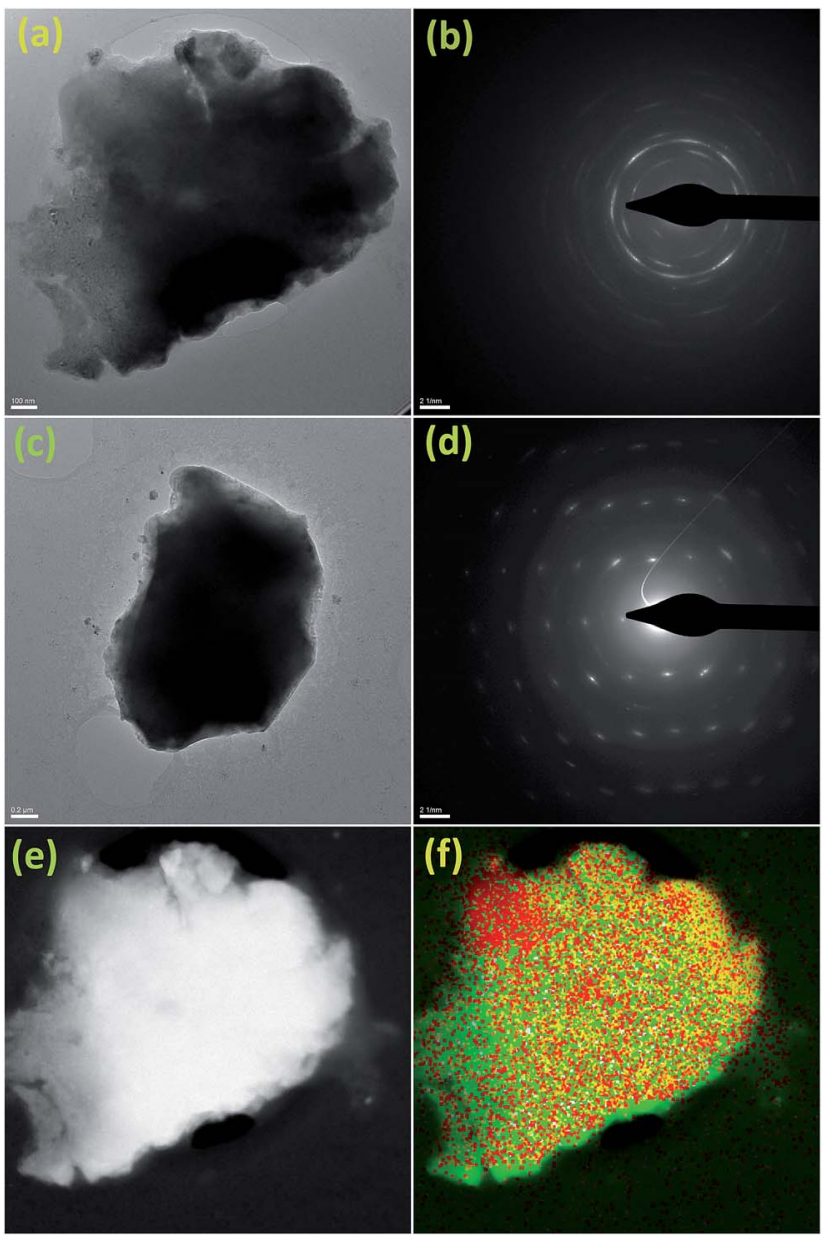

Fig. 3 High-magnification bright-field TEM images and the corresponding electron diffraction patterns of $\mathrm{Li}_{6} \mathrm{PS}_{5} \mathrm{Br}(\mathrm{a}$ and $\mathrm{b})$ and $\mathrm{AN}$ $\mathrm{BM}-\mathrm{Li}_{6} \mathrm{PS}{ }_{5} \mathrm{Br}$ (c and d). EDX mapping for the $\mathrm{Li}_{6} \mathrm{PS}{ }_{5} \mathrm{Br}$ sample (e and $\mathrm{f}$ ). The yellow, green and red dots represent the distribution of $\mathrm{S}, \mathrm{Br}$, and $P$.

micron sized isotropic particles. EDS in Fig. S3† shows that S, P and $\mathrm{Br}$ are homogeneously distributed for the three materials indicating that the first ball milling preparation step already results in a homogeneous mixture.

\section{Solid-state NMR relaxation experiments}

Measurement of the ${ }^{7} \mathrm{Li}$ spin-spin $\left(T_{2}\right)$ and spin-lattice $\left(T_{1}\right)$ relaxation times as a function of temperature provides insight into the mobility of Li-ions. ${ }^{25-27}$ The decreasing FWHM of the static ${ }^{7} \mathrm{Li}$ NMR resonances with increasing temperature observed in Fig. 4(a-c) for the three $\mathrm{Li}_{6} \mathrm{PS}_{5} \mathrm{Br}$ samples indicates increased Li-ion mobility, an effect that is referred to as motional narrowing. At lower temperatures i.e. $173 \mathrm{~K} \mathrm{the}^{7} \mathrm{Li}-{ }^{7} \mathrm{Li}$ dipolar interactions are responsible for the broad resonances observed, which are averaged out when the temperature is increased because the Li-ion hopping frequency exceeds the dipolar interaction strength. ${ }^{28}$ The low temperature static spectrum can be consistently fitted with a Gaussian line shape. The ${ }^{7} \mathrm{Li}$ resonance of the $\mathrm{AN}-\mathrm{Li}_{6} \mathrm{PS}_{5} \mathrm{Br}$ shows a much narrower line width than that of $\mathrm{Li}_{6} \mathrm{PS}_{5} \mathrm{Br}$, at $173 \mathrm{~K}$, suggesting that a larger fraction of mobile Li-ions is present in the $\mathrm{AN}-\mathrm{Li}_{6} \mathrm{PS}_{5} \mathrm{Br}$ material. The AN-BM- $\mathrm{Li}_{6} \mathrm{PS}_{5} \mathrm{Br}$ material has a larger line width than $\mathrm{AN}^{-\mathrm{Li}_{6}} \mathrm{PS}_{5} \mathrm{Br}$ and narrower line width than $\mathrm{Li}_{6} \mathrm{PS}_{5} \mathrm{Br}$. A contributing factor towards the broader lines observed for both the ball-milled samples may also be the decreased crystallinity of both the $\mathrm{Li}_{6} \mathrm{PS}_{5} \mathrm{Br}$ and $\mathrm{AN}-\mathrm{BM}-\mathrm{Li}_{6} \mathrm{PS}_{5} \mathrm{Br}$ samples. This potentially results in a distribution of chemical shifts, induced by the high energy ball-milling. Interestingly, comparing AN$\mathrm{Li}_{6} \mathrm{PS}_{5} \mathrm{Br}$ to previously studied $\mathrm{Li}_{6} \mathrm{PS}_{5} \mathrm{Cl}_{1}{ }^{17}$ the $\mathrm{Li}_{6} \mathrm{PS}_{5} \mathrm{Br}{ }^{7} \mathrm{Li}$ NMR resonance is shifted up-field to approximately $-3 \mathrm{ppm}$. This is most likely caused by the increased shielding of the Li-ions by the neighboring $\mathrm{Br}$ dopants. The motional narrowing curves of $\mathrm{Li}_{6} \mathrm{PS}_{5} \mathrm{Br}, \mathrm{AN}^{-} \mathrm{Li}_{6} \mathrm{PS}_{5} \mathrm{Br}$, and $\mathrm{AN}-\mathrm{BM}-\mathrm{Li}_{6} \mathrm{PS}_{5} \mathrm{Br}$ measured versus temperature (see Fig. $4 \mathrm{~d}$ ) are in good agreement with that published by Epp and co-workers for the $\mathrm{Li}_{6} \mathrm{PS}_{5} \mathrm{Br}$ material. ${ }^{29}$ Epp et al. measured NMR spectra at $13 \mathrm{~K}$ and obtained an onset temperature for the Li-ion mobility of $87 \mathrm{~K}$. Because of the temperature limitations of the instrument utilized for the present investigation, the measurements do not reach the socalled rigid-lattice regime where Li-ion hopping is frozen. Above room temperature, the line shape can be deconvoluted into a narrow Lorentzian and a broad Gaussian which are assigned to mobile and static Li-ion populations respectively (see ESI Fig. S1 $\dagger$ ). ${ }^{30}$ This allows us to evaluate the fraction of mobile Li-ions $\left(A_{\mathrm{f}}\right)$ in $\mathrm{Li}_{6} \mathrm{PS}_{5} \mathrm{Br}$, $\mathrm{AN}-\mathrm{Li}_{6} \mathrm{PS}_{5} \mathrm{Br}$ and $\mathrm{AN}-\mathrm{BM}-\mathrm{Li}_{6} \mathrm{PS}_{5} \mathrm{Br}$ as a function of temperature, as shown in the inset of Fig. $4 \mathrm{~d}$. At $183 \mathrm{~K}$, an $A_{\mathrm{f}}$ value of $25 \%$ was determined for $\mathrm{Li}_{6} \mathrm{PS}_{5} \mathrm{Br}$, while that for $\mathrm{AN}^{-\mathrm{Li}_{6}} \mathrm{PS}_{5} \mathrm{Br}$ and $\mathrm{AN}-\mathrm{BM}-\mathrm{Li}_{6} \mathrm{PS}_{5} \mathrm{Br}$ is approximately $50 \%$, indicating that annealing increases the amount of mobile Li-ions significantly.

To quantitatively determine the local Li-ion temperaturedependent mobility, ${ }^{7} \mathrm{Li}$ static spin-lattice relaxation (SLR) rates in the laboratory frame, $1 / T_{1}$, and in the rotating frame $1 / T_{1 \rho}$ are measured, the results of which are shown in Fig. 5. Provided that the variation of the SLR is only induced by Li-ion mobility, the temperature dependence of the SLR rate in the laboratory frame, $1 / T_{1}$, can be used to quantify the Li-ion jump frequency and the corresponding activation energy. ${ }^{27,31-33}$, The longer range ionic motion taking place at a larger time scale can be probed by SLR NMR measurements in the rotating frame. $^{27,31-33}$ The hopping frequency $1 / \tau$, where $\tau$ is the residence time, is assumed to be equal to the correlation time between hops. When $1 / T_{1(\rho)}$ reaches a maximum as a function of temperature, the hopping frequency $1 / \tau$ is in the order of the Larmor frequency $\left(\omega_{0}\right)$ or spin lock frequency $\left(\omega_{1}\right)^{27,31-33}$ In the laboratory frame, the longitudinal relaxation rate $1 / T_{1}$ reaches a maximum near $\omega_{\mathrm{o}}{ }^{2} \tau_{\mathrm{c}}{ }^{2} \approx 1$, a consequence of the effective energy transfer between the system with the diffusing atoms. The maximum relaxation rate $1 / T_{1}$ is reached at 383 for $\mathrm{Li}_{6} \mathrm{PS}_{5} \mathrm{Br}$ and $358 \mathrm{~K}$ for both $\mathrm{AN}-\mathrm{Li}_{6} \mathrm{PS}_{5} \mathrm{Br}$ and $\mathrm{AN}-\mathrm{BM}-\mathrm{Li}_{6} \mathrm{PS}_{5} \mathrm{Br}$. With a Larmor frequency of $\omega_{\mathrm{o}} / 2 \pi=155.506 \mathrm{MHz}$, the Li-ion jump frequency $1 / \tau_{\mathrm{c}}$ for the $\mathrm{Li}_{6} \mathrm{PS}_{5} \mathrm{Br}$ (at $383 \mathrm{~K}$ ) and for $\mathrm{AN}-\mathrm{Li}_{6} \mathrm{PS}_{5} \mathrm{Br}$ and $\mathrm{AN}-\mathrm{BM}-\mathrm{Li}_{6} \mathrm{PS}_{5} \mathrm{Br}$ (at $358 \mathrm{~K}$ ) can be determined to be approximately $9.810^{8} \mathrm{~s}^{-1}$, similar to what was reported previously for $\mathrm{Li}_{6} \mathrm{PS}_{5} \mathrm{Br}^{29}$ Because this jump rate is achieved at a lower temperature for both $\mathrm{AN}-\mathrm{Li}_{6} \mathrm{PS}_{5} \mathrm{Br}$ and $\mathrm{AN}-\mathrm{BM}-\mathrm{Li}_{6} \mathrm{PS}_{5} \mathrm{Br}$, 

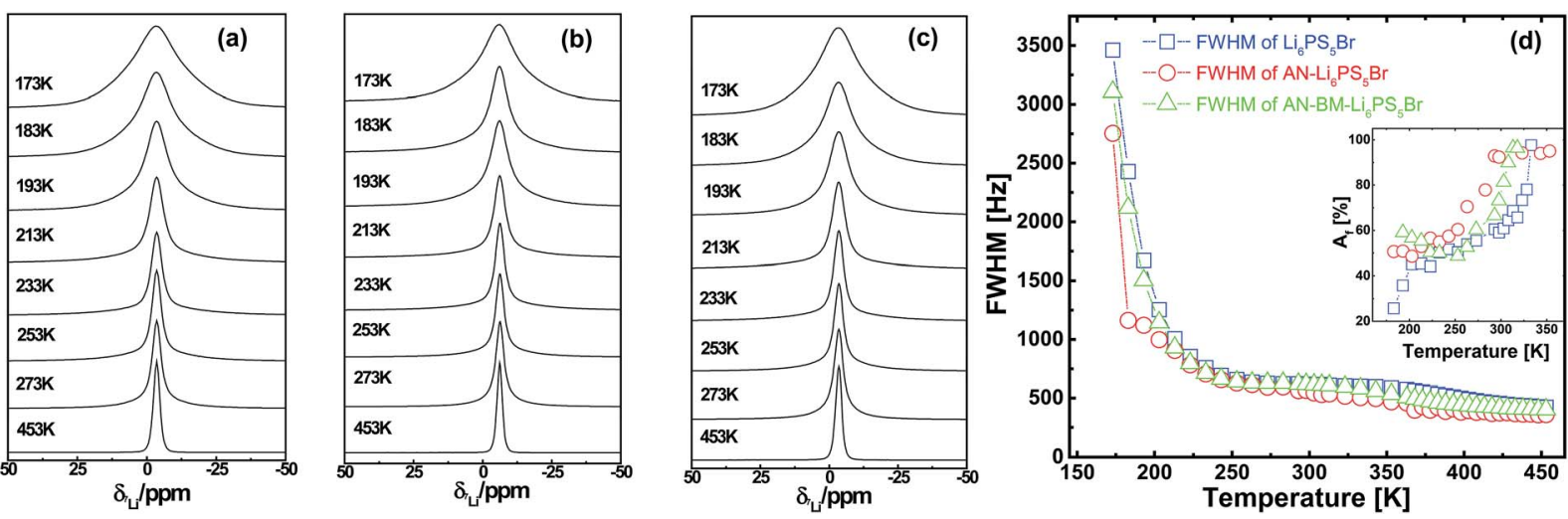

Fig. $4{ }^{7} \mathrm{Li} \mathrm{NMR}$ motional narrowing spectra of (a) $\mathrm{Li}_{6} \mathrm{PS}_{5} \mathrm{Br}$, (b) $\mathrm{AN}-\mathrm{Li}_{6} \mathrm{PS}_{5} \mathrm{Br}$ and (c) $\mathrm{AN}-\mathrm{BM}-\mathrm{Li}_{6} \mathrm{PS}{ }_{5} \mathrm{Br}$. (d) Evolution of the FWHM of the static ${ }^{7} \mathrm{Li}$ NMR resonance with temperature for $\mathrm{Li}_{6} \mathrm{PS}_{5} \mathrm{Br}, \mathrm{AN}-\mathrm{Li}_{6} \mathrm{PS}_{5} \mathrm{Br}$ and $\mathrm{AN}-\mathrm{BM}-\mathrm{Li}_{6} \mathrm{PS}{ }_{5} \mathrm{Br}$. The inset shows the fraction of the mobile $\mathrm{Li}-\mathrm{ions}$ in the three materials versus temperature.

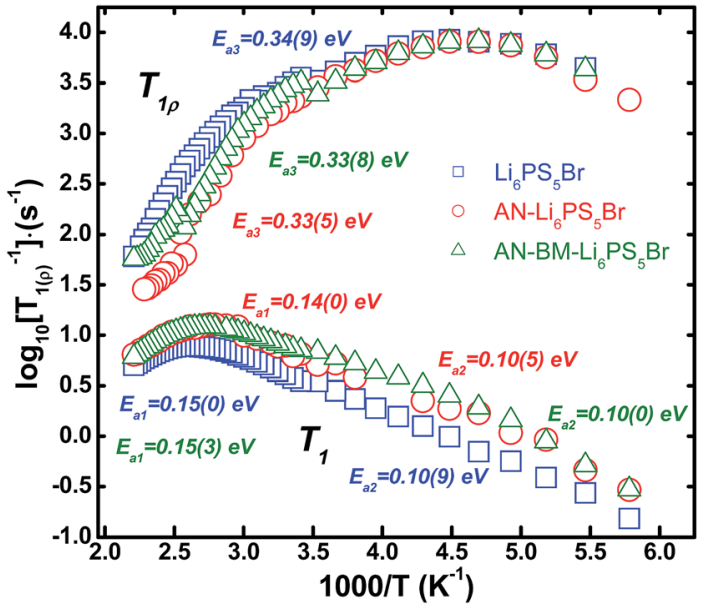

Fig. 5 Temperature dependence of the ${ }^{7} \mathrm{Li}$ spin-lattice relaxation NMR rates $T_{1(\rho)}{ }^{-1}$ measured in both the laboratory and the rotating frame of reference for the $\mathrm{Li}_{6} \mathrm{PS}_{5} \mathrm{Br}, \mathrm{AN}-\mathrm{Li}_{6} \mathrm{PS}{ }_{5} \mathrm{Br}$ and $\mathrm{AN}-\mathrm{BM}-\mathrm{Li}_{6} \mathrm{PS}{ }_{5} \mathrm{Br}$ materials. The Larmor frequency is $155.506 \mathrm{MHz}\left(T_{1}{ }^{-1}\right)$ and the spin lock frequency is $20 \mathrm{kHz}\left(T_{1 \rho}{ }^{-1}\right)$.

this indicates that these materials have a higher local Li-ion mobility compared to the $\mathrm{Li}_{6} \mathrm{PS}_{5} \mathrm{Br}$ material. Taking into account the diffraction results, the origin of the higher Li-ion mobility may be from the larger crystallinity and/or the $\mathrm{Br}$ distribution over the $4 \mathrm{a}$ and $4 \mathrm{c}$ sites. The SLR rates, $1 / T_{1}$ and $1 / T_{1 \rho}$, are directly related to the spectral density functions of the Li-ion jumping processes. ${ }^{34}$ Assuming a 3D diffusion process, in the high temperature limit, $\tau \omega_{0}<<1$, the SLR rates are proportional to the Li-ion residence time $\tau$ and in the low temperature limit, $\tau \omega_{\mathrm{o}} \gg>1$, the SLR rates are proportional to $\tau^{-1} \omega_{\mathrm{o}(\rho)}{ }^{-\beta}$ (with $1<\beta \leq 2$ ). Assuming an Arrhenius behavior for the Li-ion residence time, $\tau=\tau_{\mathrm{o}} \exp \left(-E_{\mathrm{a}} /\left(k_{\mathrm{B}} T\right)\right)$, the slope of the high and low temperature regimes of the SLR rates in Fig. 5 can be related to the activation energy for the Li-ion motional processes. The original BPP behaviour ${ }^{28}$ predicts symmetric peaks, $\beta=2$, in the SLR rate as a function of temperature which does not take into account correlation effects and disorder in diffusion. ${ }^{34}$ In particular the $1 / T_{1}$ rate appears to be asymmetric, most likely the result of Li-ion diffusional processes taking place at different length scales, illustrated by the different transitions predicted by MD simulations. ${ }^{21}$ In both the lowtemperature and high-temperature flanks, the jump rates exhibit Arrhenius behavior, yielding activation energies of 0.10(9) and 0.15(0) eV for $\mathrm{Li}_{6} \mathrm{PS}_{5} \mathrm{Br}, 0.10(5)$ and $0.14(0) \mathrm{eV}$ for AN$\mathrm{Li}_{6} \mathrm{PS}_{5} \mathrm{Br}$, and $0.10(0)$ and $0.15(3) \mathrm{eV}$ for $\mathrm{AN}-\mathrm{BM}-\mathrm{Li}_{6} \mathrm{PS}_{5} \mathrm{Br}$, respectively. The asymmetry, quantified by $\beta=1.73,1.78$ and 1.67 for $\mathrm{Li}_{6} \mathrm{PS}_{5} \mathrm{Br}, \mathrm{AN}-\mathrm{Li}_{6} \mathrm{PS}_{5} \mathrm{Br}$ and AN-BM- $\mathrm{Li}_{6} \mathrm{PS}_{5} \mathrm{Br}$, is slightly higher than the previous results reported for annealed $\mathrm{Li}_{6} \mathrm{PS}_{5} \mathrm{Br}$ probed by temperature dependent SLR NMR $\left(1 / T_{1}\right.$ and $\left.1 / T_{1 \rho}\right) .{ }^{29}$ The low temperature flank represents a short range motional process whereas the high temperature flank most likely represents longer range Li-ion resulting in actual diffusion. ${ }^{34}$ The activation energies for all three $\mathrm{Li}_{6} \mathrm{PS}_{5} \mathrm{Br}$ in the high temperature flank are close to that deduced by temperature-dependent ionic conductivity measurements reported by Rayavarapu et al. ${ }^{15}$ i.e. $0.17 \mathrm{eV}$ from 300 to $600 \mathrm{~K}$, and are slightly smaller in comparison with the $0.2 \mathrm{eV}$ reported by Epp et al. ${ }^{29}$ The activation energy for three $\mathrm{Li}_{6} \mathrm{PS}_{5} \mathrm{Br}$ samples in the low temperature flank, representing local motional processes, is approximately $0.1 \mathrm{eV}$, which is comparable to the values for the $48 \mathrm{~h}-48 \mathrm{~h}$ and intra-cage local Li-ion motional processes predicted by $\mathrm{MD}$ simulations for $\mathrm{Li}_{6} \mathrm{PS}_{5} \mathrm{Br} .^{21}$ This suggests that the $1 / T_{1}$ rates in the low temperature flank reflect local Li-ion movement inside $\mathrm{Li}_{6} \mathrm{PS}_{5} \mathrm{Br}$ similar to what was found for $\mathrm{Li}_{6} \mathrm{PS}_{5} \mathrm{Cl}{ }^{17}$

The ${ }^{7}$ Li SLR measurements in the rotating frame $\left(1 / T_{1 \rho}\right)$, also shown in Fig. 5, were performed to probe Li-ion mobility on a larger length and time scale in all three $\mathrm{Li}_{6} \mathrm{PS}_{5} \mathrm{Br}$ materials to complement the local hopping probed by $1 / T_{1}$ relaxation. In the rotating frame at a lock frequency $\omega_{\text {lock }}$, the maximum condition for the lithium jump rate is $\omega_{\text {lock }} \tau \approx 0.5 .^{35}$ The corresponding jump rates in this rotating frame (lock frequency 20 $\mathrm{kHz}$ ) are the same, $2.512 \times 10^{5} \mathrm{~s}^{-1}$ at $228 \mathrm{~K}$ for the three $\mathrm{Li}_{6}-$ $\mathrm{PS}_{5} \mathrm{Br}$ materials. This indicates that the time scale of Li-ion diffusion on a longer length scale (several hops) is comparable for all three materials. However, the activation energies for the high temperature flank of the $1 / T_{1 \rho}$ rates, observed in Fig. 5 , are considerably higher at $0.33-0.34 \mathrm{eV}$, in comparison with the 
$0.14-0.15 \mathrm{eV}$ of the high temperature flank of the $1 / T_{1}$ relaxation rates. The larger diffusion time probed by the measurement in the rotating frame suggests that not only the local bulk kinetics are probed, but also Li-ion diffusion through grain boundaries is observed. The slightly smaller activation energies of the $\mathrm{AN}$ $\mathrm{Li}_{6} \mathrm{PS}_{5} \mathrm{Br}$ and $\mathrm{AN}-\mathrm{BM}-\mathrm{Li}_{6} \mathrm{PS}_{5} \mathrm{Br}$ materials deduced from the $1 / T_{1 \rho}$ rates in the high temperature flank suggest that the annealing process promotes Li-motion in $\mathrm{Li}_{6} \mathrm{PS}_{5} \mathrm{Br}$ over longer length scales. This could suggest better mobility over grain boundaries, consistent with the lower grain boundary resistances observed for these materials with room temperature impedance spectroscopy, Fig. 1c. In summary, the ${ }^{7} \mathrm{Li}$ NMR relaxation experiments indicate slightly improved Li-ion mobility for the annealed materials both for local Li-ion hopping, and longer range diffusion, although the activation energies are very similar. The much higher activation energy for the long range diffusion, as observed from the spin-locked SRL experiments, suggests that these experiments probe the Li-ion diffusion over grain boundaries.

\section{Electrochemical performance}

When combining a cathode material with a solid electrolyte, it is essential to investigate the chemical and electrochemical stability. Nano- $\mathrm{Li}_{2} \mathrm{~S}$ was selected as the cathode material for this study and the stability and conductivity of the cathode mixture with the $\mathrm{AN}-\mathrm{Li}_{6} \mathrm{PS}_{5} \mathrm{Br}$ solid electrolyte were investigated by cyclic voltammetry (CV), powder XRD and AC impedance spectroscopy, the results of which are shown in ESI Fig. S4 and S5. $\dagger$ In the diffraction patterns of the $\mathrm{Li}_{2} \mathrm{~S}$ and $\mathrm{AN}-\mathrm{Li}_{6} \mathrm{PS}_{5} \mathrm{Br}$ mixture before and after milling and annealing, no additional diffraction peaks are detected, suggesting that nano- $\mathrm{Li}_{2} \mathrm{~S}$ is stable with the annealed $\mathrm{Li}_{6} \mathrm{PS}_{5} \mathrm{Br}$ solid electrolyte up to $180{ }^{\circ} \mathrm{C}$. Another important factor to consider is the overall conductivity of the cathode-electrolyte mixture ${ }^{36,37}$ which for the present mixture resulted in a resistance of $750 \Omega$ yielding a $\mathrm{Li}^{+}$conductivity of $\sim 10^{-4} \mathrm{~S} \mathrm{~cm}^{-1}$, indicating that this nano- $\mathrm{Li}_{2} \mathrm{~S}-\mathrm{Li}_{6} \mathrm{PS}_{5} \mathrm{Br}$ cathode mixture is a viable solid-state electrode. Initially, it has been suggested that sulfide solid electrolytes, including the presently investigated argyrodite $\mathrm{Li}_{6} \mathrm{PS}_{5} \mathrm{Br}$, have a very wide electrochemical stability window. However, recent calculations ${ }^{38,39}$ and experimental observations indicate otherwise. ${ }^{40-42}$ The performance of the all-solid-state batteries will depend on the formation of oxidation and/or reduction products at the interfaces between the electrode material and the solid electrolyte, and to what extent this hinders Li-ion transport. Previous results ${ }^{16,17}$ on the chloride doped argyrodite $\mathrm{Li}_{6} \mathrm{PS}_{5} \mathrm{Cl}$ solid electrolyte have shown that the (dis)charge voltage window has a significant influence on the electrochemical performances of these solid-state batteries. At present, the optimal (dis)charge voltage window was determined for the nano- $\mathrm{Li}_{2} \mathrm{~S} / \mathrm{AN}-\mathrm{Li}_{6} \mathrm{PS}_{5} \mathrm{Br} / \mathrm{In}$ solid-state batteries by systematic variation of the voltage window for cyclic voltammetry (CV) measurements, as shown in Fig. S5 of the ESI. $\dagger$ This indicates that, to obtain the highest apparent coulombic efficiency, the optimum charge/discharge window for this assembled nano- $\mathrm{Li}_{2} \mathrm{~S} / \mathrm{AN}-\mathrm{Li}_{6} \mathrm{PS}_{5} \mathrm{Br} / \mathrm{In}$ solid-state cell is between 0 and $3.5 \mathrm{~V} v s$. In (from 0.6 to $4.1 \mathrm{~V} v s$. $\mathrm{Li} / \mathrm{Li}^{+}$). The finding that the higher cutoff voltage during charge (i.e. $4.0 \mathrm{~V} v$ s. In) results in a lower coulombic efficiency, compared to the optimal cutoff ( $3.5 \mathrm{~V}$ vs. In), is most likely the result of more severe oxidation of the solid electrolyte, in line with the limited electrochemical stability obtained by thermodynamic predictions ${ }^{38,39}$ and experimental analysis after charging of $\mathrm{Li}_{6} \mathrm{PS}_{5} \mathrm{Cl}$ in positive electrode mixtures. ${ }^{43}$

To investigate the impact of annealing and subsequent ball milling treatment on the solid-state battery performance, cathodic mixtures of the nano- $\mathrm{Li}_{2} \mathrm{~S}$ cathode were prepared with the $\mathrm{Li}_{6} \mathrm{PS}_{5} \mathrm{Br}, \mathrm{AN}-\mathrm{Li}_{6} \mathrm{PS}_{5} \mathrm{Br}$ and $\mathrm{AN}-\mathrm{BM}-\mathrm{Li}_{6} \mathrm{PS}_{5} \mathrm{Br}$ solid electrolyte materials. In Fig. 6a, the first 4 charge/discharge curves are compared at the same current density of $0.064 \mathrm{~mA} \mathrm{~cm}^{-2}$ in the earlier determined optimal voltage window of $0-3.5 \mathrm{~V} v s$. In (0.62-4.12 V vs. $\left.\mathrm{Li}^{+} / \mathrm{Li}\right)$. The differences in capacity retention are striking, where the solid-state cell using AN-BM-Li ${ }_{6} \mathrm{PS}_{5} \mathrm{Br}$ shows a significantly better electrochemical performance when compared to that for both the $\mathrm{AN}-\mathrm{Li}_{6} \mathrm{PS}_{5} \mathrm{Br}$ and $\mathrm{Li}_{6} \mathrm{PS}_{5} \mathrm{Br}$ solid electrolyte materials. For the solid-state cell using $\mathrm{Li}_{6} \mathrm{PS}_{5} \mathrm{Br}$ as the electrolyte, the (dis)charge curves during the first four cycles show no obvious (dis)charge plateau and a very low discharge capacity, smaller than $50 \mathrm{~mA} \mathrm{~h} \mathrm{~g}{ }^{-1}$. In contrast, the charge curves of the solid-state cells with the $\mathrm{AN}-\mathrm{Li}_{6} \mathrm{PS}_{5} \mathrm{Br}$ and $\mathrm{AN}-\mathrm{BM}$ $\mathrm{Li}_{6} \mathrm{PS}_{5} \mathrm{Br}$ solid electrolytes deliver two distinct charge plateaus, located at 1.8 and $2.3 \mathrm{~V}$ vs. In, respectively and a discharge plateau located at approximately $1.4 \mathrm{~V} v s$. In. Although the AN$\mathrm{Li}_{6} \mathrm{PS}_{5} \mathrm{Br}$ solid-state cell results in a promising initial discharge capacity, it degrades to below $400 \mathrm{~mA} \mathrm{~h} \mathrm{~g}^{-1}$ within a few cycles. The best capacity retention is achieved with the AN-BM-Li ${ }_{6} \mathrm{PS}_{5} \mathrm{Br}$ solid electrolyte, resulting in a capacity of approximately $500 \mathrm{~mA} \mathrm{~h} \mathrm{~g}{ }^{-1}$ retained over 25 cycles. The initial discharge capacity is comparable to that demonstrated by $\mathrm{Li}_{2} \mathrm{~S}$ cathodes in combination with organic liquid electrolytes, which is reported to be $785 \mathrm{~mA} \mathrm{~h} \mathrm{~g}^{-1}$ at a higher rate i.e. $0.2 \mathrm{C} .{ }^{44}$ The present solidstate cell provides a higher discharge capacity and better cyclability compared to most reported comparable solid-state cells employing composite $\mathrm{Li}_{2} \mathrm{~S}$ electrodes in combination with argyrodite and $80 \mathrm{Li}_{2} \mathrm{~S}-20 \mathrm{P}_{2} \mathrm{~S}_{5}$ solid electrolytes. ${ }^{19,27}$ However, the electrochemical performance reported in this work is not as good as that for the solid-state cell in combination with a mixed-conductive $\mathrm{Li}_{2} \mathrm{~S}$ nanocomposite cathode and $\mathrm{Li}_{6} \mathrm{PS}_{5} \mathrm{Cl}$ electrolyte ${ }^{45}$ most likely due to the better distribution of $\mathrm{Li}_{2} \mathrm{~S}, \mathrm{Li}_{6} \mathrm{PS}_{5} \mathrm{Cl}$ and carbon in the cathode mixture.

During the first 5 cycles, the discharge capacity increases per cycle, which is attributed to the activation process for the $\mathrm{Li}_{2} \mathrm{~S}$ cathode mixture. However, a higher charge capacity than discharge capacity is observed over many cycles. This may indicate that not only the $\mathrm{Li}_{2} \mathrm{~S}$ cathode is oxidized but also the $\mathrm{Li}_{6} \mathrm{PS}_{5} \mathrm{Br}$ electrolyte at the interface with the $\mathrm{Li}_{2} \mathrm{~S}$ may be oxidized. Calculations indicate a very narrow stability window for argyrodite $\mathrm{Li}_{6} \mathrm{PS}_{5} \mathrm{Cl},{ }^{38,39}$ resulting in $\mathrm{S}, \mathrm{P}_{2} \mathrm{~S}_{5}$ and LiCl oxidation products above $2.3 \mathrm{~V}$ vs. $\mathrm{Li} / \mathrm{Li}^{+}$. For $\mathrm{Li}_{6} \mathrm{PS}_{5} \mathrm{Br}$ at the $\mathrm{Li}_{2} \mathrm{~S}$ interface, this suggests that cycling up to $4.12 \mathrm{~V} \mathrm{vs.} \mathrm{Li}^{+} / \mathrm{Li}$ during charge leads to the formation of $\mathrm{S}, \mathrm{P}_{2} \mathrm{~S}_{5}$ and $\mathrm{LiBr}$ in the present cells, potentially explaining the larger charge capacity observed during cycling. It should be noted that this potentially increases the amount of $\mathrm{S}$ in the cell, acting as a positive electrode 
(a)

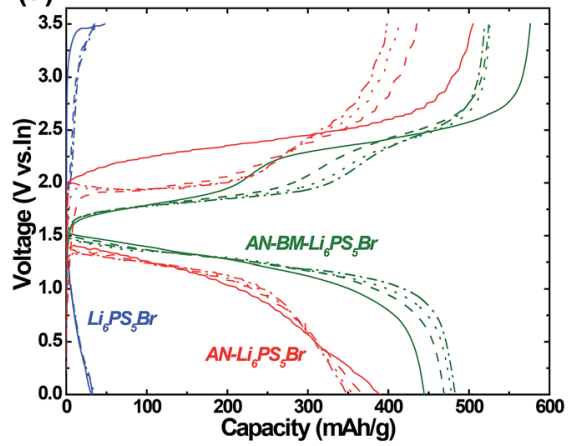

(b)

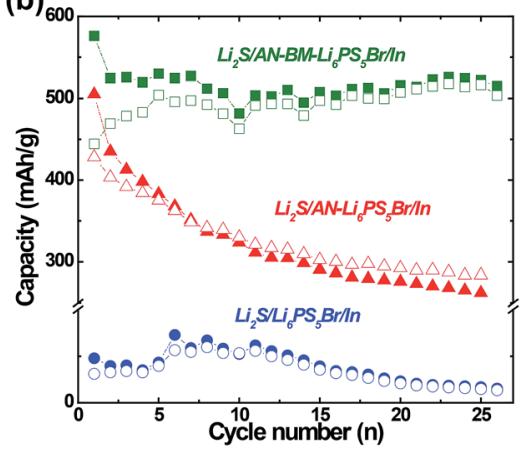

(c)

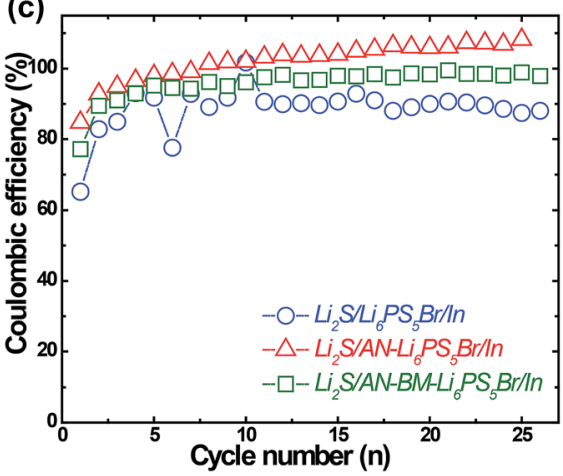

Fig. 6 (a) Galvanostatic voltage curves for the first 4 cycles of the assembled nano- $\mathrm{Li}_{2} \mathrm{~S} / \mathrm{Li}_{6} \mathrm{PS}{ }_{5} \mathrm{Br}\left(\mathrm{Li}_{6} \mathrm{PS}{ }_{5} \mathrm{Br}\right.$ or $\mathrm{AN}-\mathrm{Li}_{6} \mathrm{PS}{ }_{5} \mathrm{Br}$ or AN-BM- $\left.\mathrm{Li} \mathrm{i}_{6} \mathrm{PS} \mathrm{S}_{5} \mathrm{Br}\right) / \mathrm{In}$ solid-state batteries at a current density of $0.064 \mathrm{~mA} \mathrm{~cm}^{-2}$ applied between 0 and $3.5 \mathrm{~V}$ vs. In $\left(0.62-4.12 \mathrm{~V}\right.$ vs. $\left.\mathrm{Li}^{+} / \mathrm{Li}\right)$. The solid, dashed, dotted and dashed dotted lines represent cycles 1-4 respectively. (b) Capacity retention on cycling of the solid-state batteries at a current density of $0.064 \mathrm{~mA} \mathrm{~cm}^{-2}$ applied between 0 and $3.5 \mathrm{~V}$ vs. In $\left(0.62-4.12 \mathrm{~V} \mathrm{vs}\right.$. $\left.\mathrm{Li}^{+} / \mathrm{Li}\right)$. (c) The corresponding coulombic efficiency for the assembled nano$\mathrm{Li}_{2} \mathrm{~S} / \mathrm{Li}_{6} \mathrm{PS}{ }_{5} \mathrm{Br}\left(\mathrm{Li}_{6} \mathrm{PS}_{5} \mathrm{Br}\right.$ or $\mathrm{AN}-\mathrm{Li}_{6} \mathrm{PS}_{5} \mathrm{Br}$ or AN-BM-Li $\left.\mathrm{PS}_{5} \mathrm{Br}\right) / \mathrm{In}$ solid-state batteries. The coulombic efficiency is defined as the ratio of discharge capacity to charge capacity.

material that may participate in subsequent (dis)charge cycles. This demonstrates a compromise made in using a large cut-off potential during charge. The large cut-off potential is necessary to overcome the large internal resistance, most likely dominated by the $\mathrm{Li}_{6} \mathrm{PS}_{5} \mathrm{Br}-\mathrm{Li}_{2} \mathrm{~S}$ interface, and utilize the $\mathrm{Li}_{2} \mathrm{~S}$ capacity. At the same time, this initiates the oxidation of the $\mathrm{Li}_{6} \mathrm{PS}_{5} \mathrm{Br}$ solid electrolyte. This suggests that the poor capacity retention of the $\mathrm{AN}^{-} \mathrm{Li}_{6} \mathrm{PS}_{5} \mathrm{Br}$ material, shown in Fig. $6 \mathrm{~b}$, is related to the larger overpotentials during charge and discharge, observed in Fig. 6a, causing more severe electrolyte decomposition. As the bulk and grain boundary conductivities of the $\mathrm{AN}-\mathrm{Li}_{6} \mathrm{PS}_{5} \mathrm{Br}$ and AN-BM-Li $\mathrm{L}_{6} \mathrm{PS}_{5} \mathrm{Br}$ do not differ very much, which was concluded from impedance spectroscopy and the solid state NMR relaxation experiments, the larger overpotentials of the $\mathrm{AN}-\mathrm{Li}_{6} \mathrm{PS}_{5} \mathrm{Br}$ material must be the consequence of the larger crystallite size providing a smaller interfacial area with the $\mathrm{Li}_{2} \mathrm{~S}$ cathode and hence causing a larger interfacial resistance. Fig. $6 \mathrm{c}$ shows the corresponding coulombic efficiency of the assembled nano- $\mathrm{Li}_{2} \mathrm{~S} / \mathrm{Li}_{6} \mathrm{PS}_{5} \mathrm{Br}\left(\mathrm{Li}_{6} \mathrm{PS}_{5} \mathrm{Br}\right.$ or AN$\mathrm{Li}_{6} \mathrm{PS}_{5} \mathrm{Br}$ or AN-BM-Li ${ }_{6} \mathrm{PS}_{5} \mathrm{Br}$ //In solid-state batteries. Assuming that the larger charge capacity is the result of the oxidation of the $\mathrm{Li}_{6} \mathrm{PS}_{5} \mathrm{Br}$ solid electrolyte, ${ }^{43}$ the low coulombic efficiency of the $\mathrm{Li}_{6} \mathrm{PS}_{5} \mathrm{Br}$ sample, having the smallest crystallite size (see Table S1 $\dagger$ ) and largest fraction of the amorphous phase (see Fig. 2), may indicate that these factors promote oxidation. Consistent with this, the coulombic efficiency increases for AN-
BN-Li ${ }_{6} \mathrm{PS}_{5} \mathrm{Br}$, which has a slightly larger crystallite size and a smaller surface area (see SEM in Fig. S2 $\dagger$ ) and is less amorphous. Finally, AN-Li ${ }_{6} \mathrm{PS}_{5} \mathrm{Br}$ results in the largest coulombic efficiency, having the largest crystallite size and smallest amorphous fraction. For $\mathrm{AN}-\mathrm{Li}_{6} \mathrm{PS}_{5} \mathrm{Br}$, the coulombic efficiency even exceeds $100 \%$ starting from the $8^{\text {th }}$ cycle, however, at the same time the capacity drops dramatically, making it hard to assess what is the origin of this effect.

In contrast, the larger interfacial area provided by the ANBM- $\mathrm{Li}_{6} \mathrm{PS}_{5} \mathrm{Br}$ material results in lower overpotentials. This appears to cause the stabilization of the $\mathrm{Li}_{6} \mathrm{PS}_{5} \mathrm{Br}$, as the differences of (dis)charge capacity in Fig. 6 become smaller upon cycling. Hence, despite the suggested formation of an oxidation layer at the $\mathrm{Li}_{6} \mathrm{PS}_{5} \mathrm{Br}-\mathrm{Li}_{2} \mathrm{~S}$ interface, as well as the large volumetric changes that occur upon $\mathrm{Li}_{2} \mathrm{~S}$ oxidation, these solid-state cells provide a relatively constant capacity retention, at least up to 25 cycles.

\section{Conclusions}

The impedance spectra in Fig. 1c indicate a significant increase in the bulk conductivity upon annealing the $\mathrm{Li}_{6} \mathrm{PS}_{5} \mathrm{Br}$ material $\left(\mathrm{AN}^{-} \mathrm{Li}_{6} \mathrm{PS}_{5} \mathrm{Br}\right)$ prepared by ball milling. The NMR relaxation experiments in Fig. 4 and 5 show that the bulk Li-ion mobility is only marginally improved, and that the increase in conductivity should be mainly attributed to the larger fraction of mobile Li- 
ions. This increase is most likely due to the presence of the increased crystalline fraction shown by XRD and TEM in Fig. 2 and 3, which is known to display a better mobility. ${ }^{46}$ Additionally, the simultaneous refinements of the neutron and X-ray diffraction data suggest that the conductivity may be inhomogeneous due to differences in the $\mathrm{Br}$ dopant distribution throughout the $\mathrm{Li}_{6} \mathrm{PS}_{5} \mathrm{Br}$ particles. Although the $\mathrm{Br}$ dopant appears to be homogeneously distributed over the material, it is not homogeneously distributed over the two crystallographic sites. For the annealed materials, $\mathrm{AN}-\mathrm{Li}_{6} \mathrm{PS}_{5} \mathrm{Br}$ and $\mathrm{AN}-\mathrm{BM}-\mathrm{Li}_{6}$ $\mathrm{PS}_{5} \mathrm{Br}$, the site distribution appears to be more favorable for a high conductivity in the crystalline fraction that forms due to the annealing process. An interesting future research direction may be to investigate the role of these distributions on solidstate battery performance, and synthesis routes to control the site distribution of the halogen dopant.

Annealing lowers the grain boundary resistance dramatically, whereas subsequent ball milling results in a slight increase in grain boundary resistance. Compared to the $T_{1}$ NMR relaxation experiments, the $T_{1 \rho}$ experiments probe a longer diffusion length scale. The much larger activation energy deduced from the $T_{1 \rho}$ experiments suggests that this includes diffusion across grain boundaries. However, these larger activation energies changed only marginally with the annealing and the ball milling treatment, suggesting that this does not change the Li-ion dynamics across the grain boundary regions. This also suggests that at the $\mathrm{Li}_{6} \mathrm{PS}_{5} \mathrm{Br}-\mathrm{Li}_{6} \mathrm{PS}_{5} \mathrm{Br}$ interfaces, a larger crystalline fraction is beneficial for the conductivity, most likely increasing the fraction of mobile ions at the interface, rather than the mobility itself. Additionally, we anticipate that the inhomogeneous distribution of Br over the two crystallographic sites may be at least partially responsible for the larger Li-ion mobility at the interfaces.

Both impedance spectroscopy and NMR experiments indicate a very similar bulk and grain boundary Li-ion mobility for the annealed ( $\mathrm{AN}-\mathrm{Li}_{6} \mathrm{PS}_{5} \mathrm{Br}$ average crystallite size $74 \mathrm{~nm}$ ) and additionally ball milled ( $\mathrm{AN}-\mathrm{BM}-\mathrm{Li}_{6} \mathrm{PS}_{5} \mathrm{Br}$ average crystallite size $22 \mathrm{~nm}$ ) materials. However, the solid-state battery with the AN$\mathrm{BM}-\mathrm{Li}_{6} \mathrm{PS}_{5} \mathrm{Br}$ electrolyte provides much better capacity retention upon cycling. The smaller particles of the annealed and ball milled material, $\mathrm{AN}-\mathrm{BM}-\mathrm{Li}_{6} \mathrm{PS}_{5} \mathrm{Br}$, appear essential for stable capacity retention, most likely through the establishment of more abundant interfacial contacts with the $\mathrm{Li}_{2} \mathrm{~S}$ cathode resulting from the higher surface area of the small solid electrolyte particles, lowering the interfacial resistance. These results indicate a difference in demands for the solid electrolyte in the solid electrolyte region of the cell compared to the solid electrolyte in the cathode mixture. In the solid electrolyte region, the lowest overall resistance dominated by the grain boundary resistance is achieved for the annealed material (AN$\mathrm{Li}_{6} \mathrm{PS}_{5} \mathrm{Br}$ ), whereas smaller solid electrolyte particle sizes are required to provide sufficient solid electrolyte-cathode interfaces, to minimize the resistance of this rate limiting Li-ion transport step.

In conclusion, the internal resistance of the solid electrolyte is dominated by the solid electrolyte-solid electrolyte $\mathrm{Li}_{6} \mathrm{PS}_{5} \mathrm{Br}$ interfaces, lowering of which can be achieved by annealing treatment. The results indicate that an inhomogeneous distribution of the Br dopant over the crystallite sites may play an important role in the conductivity at the interfaces. The largest contributor to the internal resistance of the $\mathrm{Li}_{2} \mathrm{~S} / \mathrm{Li}_{6} \mathrm{PS}_{5} \mathrm{Br} / \mathrm{In}$ solid-state battery appears to exist at the $\mathrm{Li}_{6} \mathrm{PS}_{5} \mathrm{Br} / \mathrm{Li}_{2} \mathrm{~S}$ interface. To utilize a majority of the $\mathrm{Li}_{2} \mathrm{~S}$ capacity, a large overpotential is required, even at the low currents. This compromises the electrochemical stability of the $\mathrm{Li}_{6} \mathrm{PS}_{5} \mathrm{Br}$ solid electrolyte, most likely leading to oxidation products. Despite the electrochemical instability at the $\mathrm{Li}_{6} \mathrm{PS}_{5} \mathrm{Br} / \mathrm{Li}_{2} \mathrm{~S}$ interface and the large volumetric changes upon charging $\mathrm{Li}_{2} \mathrm{~S}$, the capacity retention of this all-solid-state battery is promising, most likely because of the abundant $\mathrm{Li}_{6} \mathrm{PS}_{5} \mathrm{Br} / \mathrm{Li}_{2} \mathrm{~S}$ interfaces that provide sufficient Li-ion conductivity and the large fraction of $\mathrm{Li}_{6} \mathrm{PS}_{5} \mathrm{Br}$ in the positive electrode mixture. Evidently, the improvement of these solid-state battery systems requires focusing on the stabilization of the solid electrolyte-electrode interfaces, to prevent both electrochemical instabilities and volumetric changes. Additionally, the present results indicate the importance of inhomogeneity in the conductivity and the importance of distinguishing between the electrolyte properties only in the electrolyte region and the electrolyte in the cathode mixture.

\section{Conflicts of interest}

There are no conflicts of interest to declare.

\section{Acknowledgements}

The research leading to these results has received funding from the European Research Council under the European Union's Seventh Framework Programme (FP/2007-2013)/ERC Grant Agreement no. [307161] of M.W. Support from the Dutch organization of scientific research (NWO) for the solid-state NMR facility for advanced materials science in Nijmegen is gratefully acknowledged. The technical assistance of Hans Janssen, Gerrit Janssen and Jan Schoonbrood is gratefully acknowledged. The solid-state NMR facility for advanced material science at the Radboud University is greatly acknowledged for supporting this research. Neutron diffraction assistance of Kees Goubitz is also gratefully acknowledged.

\section{References}

1 J. W. Fergus, J. Power Sources, 2010, 195, 4554-4569.

2 P. Knauth, Solid State Ionics, 2009, 180, 911-916.

3 Y. S. Jung, D. Y. Oh, Y. J. Nam and K. H. Park, Isr. J. Chem., 2015, 55, 472-485.

4 J. C. Bachman, S. Muy, A. Grimaud, H.-H. Chang, N. Pour, S. F. Lux, O. Paschos, F. Maglia, S. Lupart and P. Lamp, Chem. Rev., 2015, 116, 140-162.

5 F. Mizuno, A. Hayashi, K. Tadanaga and M. Tatsumisago, Adv. Mater., 2005, 17, 918-921.

6 N. Kamaya, K. Homma, Y. Yamakawa, M. Hirayama, R. Kanno, M. Yonemura, T. Kamiyama, Y. Kato, S. Hama, K. Kawamoto and A. Mitsui, Nat. Mater., 2011, 10, 682-686. 
7 H.-J. Deiseroth, S.-T. Kong, H. Eckert, J. Vannahme, C. Reiner, T. Zaiß and M. Schlosser, Angew. Chem., Int. Ed., 2008, 47, 755-758.

8 V. Thangadurai, S. Narayanan and D. Pinzaru, Chem. Soc. Rev., 2014, 43, 4714-4727.

9 H. Aono, E. Sugimoto, Y. Sadaoka, N. Imanaka and G. y. Adachi, J. Electrochem. Soc., 1990, 137, 1023-1027.

10 J. G. Kim, B. Son, S. Mukherjee, N. Schuppert, A. Bates, O. Kwon, M. J. Choi, H. Y. Chung and S. Park, J. Power Sources, 2015, 282, 299-322.

11 C. Cao, Z.-B. Li, X.-L. Wang, X.-B. Zhao and W.-Q. Han, Frontiers in Energy Research, 2014, 2, 25.

12 K. Takada, Acta Mater., 2013, 61, 759-770.

13 Y. Seino, T. Ota, K. Takada, A. Hayashi and M. Tatsumisago, Energy Environ. Sci., 2014, 7, 627-631.

14 R. P. Rao, N. Sharma, V. K. Peterson and S. Adams, Solid State Ionics, 2013, 230, 72-76.

15 P. Rayavarapu, N. Sharma, V. Peterson and S. Adams, J. Solid State Electrochem., 2012, 16, 1807-1813.

$16 \mathrm{C}$. Yu, S. Ganapathy and M. Wagemaker, Electrochim. Acta, 2016, 215, 93-99.

17 C. Yu, S. Ganapathy, N. J. de Klerk, I. Roslon, E. R. Van Eck, A. P. Kentgens and M. Wagemaker, J. Am. Chem. Soc., 2016, 138, 11192-11201.

18 S. Boulineau, M. Courty, J.-M. Tarascon and V. Viallet, Solid State Ionics, 2012, 221, 1-5.

19 M. Chen, R. P. Rao and S. Adams, Solid State Ionics, 2014, 262, 183-187.

20 W. D. Richards, L. J. Miara, Y. Wang, J. C. Kim and G. Ceder, Chem. Mater., 2015, 28, 266-273.

21 N. J. de Klerk, I. Roslon and M. Wagemaker, Chem. Mater., 2016, 28, 7955-7963.

22 L. van Eijck, L. D. Cussen, G. J. Sykora, E. M. Schooneveld, N. J. Rhodes, A. A. van Well and C. Pappas, J. Appl. Crystallogr., 2016, 49, 1398-1401.

23 B. H. Toby, J. Appl. Crystallogr., 2001, 34, 210-213.

24 S. Ujiie, A. Hayashi and M. Tatsumisago, Solid State Ionics, 2012, 211, 42-45.

25 M. Wagemaker, Structure and Dynamics of Lithium in Anatase $\mathrm{TiO}_{2}$, TU Delft, Delft University of Technology, 2003.

26 M. Wagemaker, R. van de Krol, A. P. M. Kentgens, A. A. van Well and F. M. Mulder, J. Am. Chem. Soc., 2001, 123, 1145411461.

27 M. Wilkening and P. Heitjans, ChemPhysChem, 2012, 13, 5365.
28 N. Bloembergen, E. M. Purcell and R. V. Pound, Phys. Rev., 1948, 73, 679-712.

29 V. Epp, Ö. Gün, H.-J. Deiseroth and M. Wilkening, J. Phys. Chem. Lett., 2013, 4, 2118-2123.

30 A. Gupta, R. Murugan, M. P. Paranthaman, Z. Bi, C. A. Bridges, M. Nakanishi, A. P. Sokolov, K. S. Han, E. W. Hagaman, H. Xie, C. B. Mullins and J. B. Goodenough, J. Power Sources, 2012, 209, 184-188.

31 V. Epp and M. Wilkening, in Handbook of Solid State Batteries, World Scientific, 2nd edn, 2015, pp. 133-190, DOI: 10.1142/9789814651905_0005.

32 A. Kuhn, M. Kunze, P. Sreeraj, H. D. Wiemhoefer, V. Thangadurai, M. Wilkening and P. Heitjans, Solid State Nucl. Magn. Reson., 2012, 42, 2-8.

33 A. Kuhn, S. Narayanan, L. Spencer, G. Goward, V. Thangadurai and M. Wilkening, Phys. Rev. B: Condens. Matter Mater. Phys., 2011, 83, 094302.

34 P. Heitjans and J Kärger, Diffusion in Condensed Matter Methods, Materials, Models, Springer, Berlin, 2005.

35 A. Kuhn, J.-Y. Choi, L. Robben, F. Tietz, M. Wilkening and P. Heitjans, Z. Phys. Chem., 2012, 226, 525-537.

36 C. Yu, H. Wang, X. Guan, J. Zheng and L. Li, J. Alloys Compd., 2013, 546, 239-245.

37 M. Park, X. Zhang, M. Chung, G. B. Less and A. M. Sastry, J. Power Sources, 2010, 195, 7904-7929.

38 W. D. Richards, L. J. Miara, Y. Wang, J. C. Kim and G. Ceder, Chem. Mater., 2016, 28, 266-273.

39 Y. Zhu, X. He and Y. Mo, ACS Appl. Mater. Interfaces, 2015, 7, 23685-23693.

40 A. Sakuda, A. Hayashi and M. Tatsumisago, Chem. Mater., 2010, 22, 949-956.

41 A. Sakuda, A. Hayashi, T. Ohtomo, S. Hama and M. Tatsumisago, J. Power Sources, 2011, 196, 6735-6741.

42 H. Visbal, Y. Aihara, S. Ito, T. Watanabe, Y. Park and S. Doo, J. Power Sources, 2016, 314, 85-92.

43 J. Auvergniot, A. Cassel, J.-B. Ledeuil, V. Viallet, V. Seznec and R. Dedryvère, Chem. Mater., 2017, 29, 3883-3890.

44 Z. W. Seh, H. Wang, P.-C. Hsu, Q. Zhang, W. Li, G. Zheng, H. Yao and Y. Cui, Energy Environ. Sci., 2014, 7, 672-676.

45 F. Han, J. Yue, X. Fan, T. Gao, C. Luo, Z. Ma, L. Suo and C. Wang, Nano Lett., 2016, 16, 4521-4527.

46 A. Hayashi, K. Noi, N. Tanibata, M. Nagao and M. Tatsumisago, J. Power Sources, 2014, 258, 420-423. 